Revista Tecné, Episteme y Didaxis: TED. Año 2014, Número Extraordinario. ISSN Impreso: 0121-3814, ISSN web: 2323-0126

Memorias, Sexto Congreso Internacional sobre Formación de Profesores de Ciencias. 08 al 10 de octubre de 2014, Bogotá

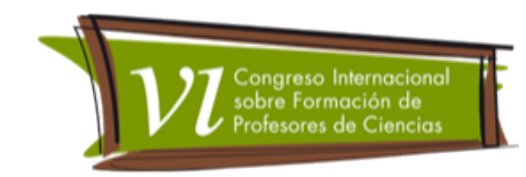

\title{
Los Animales Y Sus Huellas: Conocimientos Y Saberes E Implicaciones En El Aula De Ciencias.
}

Castillo Rodas Andrea', Venegas Segura Andrés Arturo²

Categoría 2. Trabajo de investigación

\section{Resumen}

El artículo presenta los conocimientos y saberes que se hallaron con referencia a las huellas de los animales desde la experiencia de aula llevada a cabo en la Institución Educativa Rural Luis Antonio Robles del Corregimiento de Camarones de grado quinto y con los niños y niñas pertenecientes a la Comunidad Indígena Wayúu (Loma Fresca y Tocoromana) del resguardo Perrapu, Municipio de Riohacha, Guajira. Investigación de corte etnográfica que identifico que el discurso sobre los animales gira en torno: a su origen; al reconocimiento por medio de sus huellas; a la clasificación y agrupaciones; a los factores para la formación y utilidad de las huellas, bajo este tipo de investigación se plantea la indagación a partir del dialogo con los estudiantes y el uso de instrumentos como encuestas y cuestionarios en los cuales se pregunta sobre el origen de los animales y las huellas como herramienta de reconocimiento. En la investigación se encuentran que los estudiantes poseen conocimientos de tipo cotidiano, ancestral, escolar y biológico que se expresan con igual importancia en su discurso. Se concluye que es vital la recuperación de la experiencia para llevar a cabo procesos de enseñanza y aprendizaje adecuados que permiten entender los marcos de referencia presentes en los estudiantes.

\section{Palabras Claves}

Conocimientos y Saberes, Comunidad Wayúu, Animales y Huellas.

\section{Introducción y Objetivos}

El objetivo de la comunicación es mostrar los conocimientos y saberes de tipo ancestral, cotidiano, biológico y científico en torno a los animales y sus huellas, por parte de los estudiantes IER Luis Antonio Robles de grado quinto y los niños y niñas

\footnotetext{
1 Licenciada en Biología. Universidad Distrital Francisco José de Caldas andreacastillorodas@gmail.com

${ }^{2}$ CDr en Educación. Universidad Distrital Francisco José de Caldas. Andresvs85@yahoo.com
} 
Revista Tecné, Episteme y Didaxis: TED. Año 2014, Número Extraordinario. ISSN Impreso: 0121-3814, ISSN web: 2323-0126

Memorias, Sexto Congreso Internacional sobre Formación de Profesores de Ciencias. 08 al 10 de octubre de 2014, Bogotá

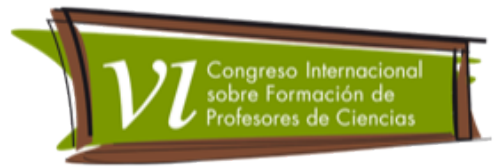

Wayúu (Loma Fresca y Tocoromana) del resguardo Perrapu. En este marco, los conocimientos y saberes se convierten en el punto de partida que da origen a ideas y postulados que se consolidan dentro de las sociedades, logrando la construcción colectiva de prácticas que permiten la convivencia entre unos y otros mediante la creación de leyes, mitos y jerarquías sociales (De Agüero, 2011). Tanto conocimientos como saberes, se encuentran estrechamente ligados a la dimensión histórica.

\section{Marco conceptual}

Los conocimientos y saberes de los niños y las niñas se encuentran en un constante dialogo, se fundamentan en sus diversos contextos que relacionan múltiples experiencias en el mundo, y permiten los procesos de conocer (Candela, 2006). En este sentido, el conocimiento escolar permite la construcción y configuración de otros contextos (García, 1997), mediados por el conocimiento científico y el conocimiento cotidiano pues no es un conocimiento que se aplique ampliamente en la vida cotidiana, ni tampoco traduce tal cual los modelos y teorías propios de las ciencias, sin embargo, éstos se encuentran relacionados a él ya que tanto conocimiento cotidiano como científico se integran en el conocimiento escolar (Arnay, 1997).

Para Candela (2006) el desarrollo de teorías en este campo del conocimiento debe generarse a partir de experiencias etnográficas que describan la realidad del conocimiento científico escolar de acuerdo al contexto en el cual se trabaja y no desde supuestos psicológicos ajenos a las aulas de clase, escenario en el cual este conocimiento se desarrolla. De acuerdo a lo anterior, la presente investigación presenta los conocimientos y saberes que presentan los niños y las niñas Wayúu con referencia a los animales y sus huellas.

\section{Diseño Metodológico}

La metodología de este proyecto de investigación es hermenéutica y etnográfica en el cual se pretende el reconocimiento de los saberes y conocimientos presentes en los niños y niñas El diseño se dividió en las siguientes fases: Documentación, consistió en la recopilación bibliográfica realizada a lo largo de toda la investigación; Campo, se realizó el taller "Historias detrás de una huella", que reconoció ciertos saberes y conocimientos relacionados a los animales y sus huellas dentro de la comunidad; Análisis, se realizó una base de datos con la información obtenida en el trabajo de campo, posteriormente se interpretó y 
Revista Tecné, Episteme y Didaxis: TED. Año 2014, Número Extraordinario. ISSN Impreso: 0121-3814, ISSN web: 2323-0126

Memorias, Sexto Congreso Internacional sobre Formación de Profesores de Ciencias. 08 al 10 de octubre de 2014, Bogotá

categorizo la información obtenida en nueve Categorías de Análisis. Las categorías de análisis (Biodiversidad, Espacial, Naturalista, Estética, Ética, Cosmológica, Útil, Emocional, Ecológica) que se articulan en los resultados de la investigación.

\section{Resultados}

Para el presente artículo se analizara el ítem: El origen de los animales, en el cual se relacionan elementos del conocimiento científico - escolar, cotidiano y biológico.

Para los niños el origen de los animales se encuentra relacionado a las zonas donde se encuentran, ellos suelen decir que los animales vienen de sitios como la selva o el bosque, aspecto abordado en sus clases de ciencias. Además, otra fuente de la información son los programas de televisión que se entrelazan con la escuela, ya que muchos afirman que los animales vienen de África, siendo esta una de la teoría más aceptada sobre el origen del hombre que fácilmente los estudiantes pueden relacionar con el origen de los animales. Por otro lado, algunos niños y niñas hacen referencia a lugares propios de la mitología como son el río magdalena y la Sierra Nevada de Santa Marta. De acuerdo a lo anterior se expone como el origen de los animales se encuentra en relación con el espacio que ocupan y con los lugares donde viven, con lo cual, resulta útil categorizar estas argumentos en una categoría espacial (Molina, Mojica, \& López, 2005; Venegas, 2012). Así, los niños y niñas dan respuestas como:

- "De las selvas o de las montañas de los bosques y de algunas partes" (A, $2011)$

- "Los animales vienen del monte, bosque del cector" (D, 2011),

- "Los animales vienen del bosque y de la selva en el desierto" (M, 2011),

- "Vienen de la Selva, vienen de Africa y vienen de mu y lejos" (C, 2011),

- "Los animales viven en la selva, monte, pueblos, en las montañas y en los paisajes glaciales y no glaciales" (Q, 2011).

Desde el punto de vista de su contexto, los animales para los Wayúu se encuentran asociados al espacio y a la mitología de origen de la comunidad. Por otro lado, los pobladores de esta región utilizan estos lugares para cazar, recolectar su alimento, vivir, todos ellos se encuentran regulados en su cosmovisión. De esta forma, los lugares otorgan una idea sobre el aprendizaje de 
Revista Tecné, Episteme y Didaxis: TED. Año 2014, Número Extraordinario. ISSN Impreso: 0121-3814, ISSN web: 2323-0126

Memorias, Sexto Congreso Internacional sobre Formación de Profesores de Ciencias. 08 al 10 de octubre de 2014, Bogotá

tipo cosmológico, escolar y cotidiano que poseen los estudiantes, pues al mencionar un espacio, tipo de paisaje o un lugar cercano a su realidad se evidencia la relación que tiene el aprendizaje con su cotidianidad.

Así, cuando los estudiantes mencionan sitios que no son cercanos a su diario vivir, referencian lo que han visto o han aprendido en escenarios como la escuela o a través los medios de comunicación. Un ejemplo de lo anterior es la afirmación, "Afica es donde queda la selva de los animales viven toda clase de animal serpiente, cocodrilo, tigre y son animales salvajes..." (S, 2011). En esta expresión África es un lugar que hace referencia a sus aprendizajes escolares dado que allí se encuentran elementos propios de las clases de ciencias como, las selvas; aunque África es un sitio muy apartado de su realidad éste es conocido por el estudiante, quien lo caracteriza como un lugar con una alta variedad de animales; y algunos diferentes a los que se encuentran en su entorno cercano.

Asimismo se encuentran lugares de índole cosmológico relacionados con el origen de los animales como La sierra Nevada de Santa Marta, frente a ella los niños expresan, "Los animales vienen de las montañas donde ha y todas las animales los animales que vienen de las montañas son el tigre el leon cocodrilos tortugas los leones vienes de las sierra nevada de santa marta por los rios..." (B, 2011), en esta afirmación la procedencia de los animales corresponde a las montañas, éstas son la Sierra Nevada de Santa Marta. Otro sitio que cita el estudiante es el río importante para el desplazamiento de ciertos animales como el león y el tigre. En consecuencia, la expresión "Los animales vienen del Rio Magdalena..." (F, 2011), permite referenciar el río Magdalena como el sendero por el cual los animales llegaron a La Guajira, constituyéndose en un espacio de importancia cosmológica, el cual se referencia en historias propias de la comunidad Wayuu.

Es de resaltar que la relación con el espacio no es solo de orden cosmológico, sino de un manejo regulado del espacio, donde emergen aspectos éticos, de esta forma los niños expresan, "... ellos [los animales] cuidan mucho su tierra y si van mejor que se queden y a eso es todo" ( $E, 2011)$, en este argumento se encuentra como la "tierra" es una expresión de cuidado y responsabilidad que tienen los animales con ella; adquiere un significado más cercano a la noción de "madre naturaleza", con un sentido ético, de pertenencia ya que los animales son responsables de su cuidado. 
Revista Tecné, Episteme y Didaxis: TED. Año 2014, Número Extraordinario. ISSN Impreso: 0121-3814, ISSN web: 2323-0126

Memorias, Sexto Congreso Internacional sobre Formación de Profesores de Ciencias. 08 al 10 de octubre de 2014, Bogotá

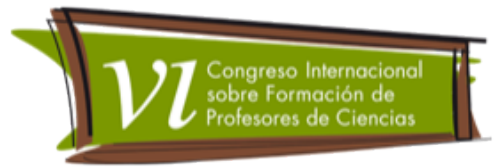

Otro tipo de sitios son agrupados por los niños y las niñas según sus características climáticas y del paisaje como se puede ver en la siguiente respuesta: "Los animales vienen desde bosques y tierras calidas..." (Y, 2011), esta permite ver como el estudiante guiado por una característica climática clasifica el entorno, cuando se menciona, "tierras cálidas", se infiere una tierra fría, este tipo de agrupación es propia del lenguaje común. En contraste, un ejemplo de clasificación de los lugares se puede ver en la expresión, "Los animales viven (...) en los paisajes glaciales y no glaciales" (Q, 2011). En esta se utiliza una clasificación que es propia de las ciencias escolares o de los medios de comunicación, pues los glaciales no hacen parte del diario vivir de los estudiantes.

\section{Conclusiones}

Los elementos del conocimiento científico sirven de herramienta para la indagación de saberes cotidianos, de igual forma los saberes cotidianos son el punto de partida desde el cual los estudiantes construyen y dan sentido a lo que aprende (Aragón, 2007). Así, los conocimientos cotidianos permiten a los estudiantes dar una explicación sobre el origen de los animales y relacionar dicho origen con eventos cotidianos y científicos propios de los animales, siendo la cotidianidad el punto de partida desde el cual se integran los nuevos conceptos; de tal forma, entre más cercanos sean los conceptos a la cotidianidad más fácil será para los estudiantes construir un nuevo cuerpo de conocimiento acerca de los animales y su origen.

Los medios de comunicación también forman parte del cuerpo de conocimiento de los estudiantes y son fuente vital de información acerca del origen de los animales, de acuerdo a estos conocimientos los estudiantes relacionan información de lo visto en los medios con lo que viven en su cotidianidad. De acuerdo a esto Bringas (2004) afirma,

"Los medios de comunicación masiva hoy en día son de vital importancia para la sociedad ya que estos (...) proporcionan casi el cien por ciento de la información que sucede en el mundo. En esta era tecnológica, las personas son más dependientes de los medios, (...), es decir básicamente los medios están presentes en la vida cotidiana de los seres humanos" (pág. 1)

En este sentido, los medios de comunicación se integran de forma exitosa a la cotidianidad de los estudiantes y les permiten acercarse al entendimiento 
Revista Tecné, Episteme y Didaxis: TED. Año 2014, Número Extraordinario. ISSN Impreso: 0121-3814, ISSN web: 2323-0126

Memorias, Sexto Congreso Internacional sobre Formación de Profesores de Ciencias. 08 al 10 de octubre de 2014, Bogotá

científico, social, y cultural de los animales y sus huellas; así como su origen desde perspectivas cercanas a otras realidades, siendo más fácil la aprensión e integración de conceptos desde los medios de comunicación, que aquellos términos y conceptos cercanos a la ciencia que actualmente son utilizados en las aulas de clase.

Para finalizar se encuentra como los aspectos propios de su cosmovisión se hacen presentes en sus discursos de forma fuerte, y se insiste en la incorporación de estos en las clases de ciencias y las temáticas con la fauna para que el conocimiento que se recree tenga mayor impacto y además se acerque más a un conocimiento integral sobre los animales, sus relaciones, sus comportamientos, entre otros aspectos.

\section{Referencias bibliográficas}

Aragón M. (2007). Reseña de "relaciones entre el conocimiento cotidiano y el conocimiento científico: comprendiendo cómo cambia la materia" de Gómez M.A. y Pozo J.I. Cádiz, España: Revista Eureka sobre Enseñanza y Divulgación de las Ciencias, v. 4, N. 2, Asociación de profesores y amigos de la Ciencia Eureka, pág. 367-371.

Arnay J. (1997). Reflexiones para un debate sobre la construcción del conocimiento en la escuela: hacia una cultura científica escolar. En Rodrigo \& Arnay (Comps). La construcción del conocimiento escolar. Barcelona, España: Editores Paidós. pág. 35-58.

Bringas V. (2004). Representación de América Latina en la revista National Geographic en Español. Puebla, México. Universidad de las Américas Puebla.

Candela, A. (2006). Del conocimiento extraescolar al conocimiento científico escolar: Un estudio etnográfico en aulas de la escuela primaria. Revista Mexicana de Investigación Educativa. pág. 797-820.

De Agüero M., (2011). Conceptualización de los saberes y el conocimiento. Revista Desicio: Saber para la acción de la educación en los adultos, N. 30 (Sep/Dic), Ciudad de México, México. Universidad Iberoamericana.

Molina, A., Mojica, L. \& López, D. (2005). Ideas de los niños y niñas sobre la naturaleza: estudio comparado. En: Revista Científica, (7). 
Revista Tecné, Episteme y Didaxis: TED. Año 2014, Número Extraordinario. ISSN Impreso: 0121-3814, ISSN web: 2323-0126

Memorias, Sexto Congreso Internacional sobre Formación de Profesores de Ciencias. 08 al 10 de octubre de 2014, Bogotá

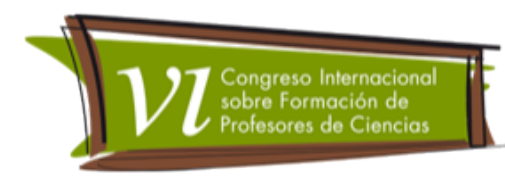

Venegas, S.A.A. (2012). Criterios De Análisis en la Interpretación de las Ideas de Naturaleza con el Conglomerado De Relevancias. Revista Científica. 16, pág. 130-140 